\title{
CEBS: UMA IGREJA QUE NASCE DO POVO
}

\section{CEBS: A CHURCH BORN OF THE PEOPLE}

Antonio Alvimar Souza ${ }^{1}$

RESUMO: O artigo em questão discute a emergência de uma eclesiologia que parte das reflexões oriundas do Concílio Vaticano II e que foram de fundamental importância para colocar as sementes de uma nova possibilidade de Igreja que coloca seus fundamentos nas experiências das comunidades. Discute a nova possibilidade eclesiológica que resultou em uma Igreja que nasce das experiências das comunidades de base. Nova experiência eclesial que alinha fé, organização social, estudo da palavra de Deus e participação política. O artigo busca costurar elementos conciliares e as experiências dos encontros dos bispos nas conferências do episcopado latino-americano.

Palavras-chaves: Igreja, Comunidade, Cebs, Popular.

ABSTRACT: The article in question discusses the emergence of an ecclesiology which part of the reflections from Vatican II and which were of fundamental importance to put the seeds of a new possibility of Church which puts their submissions on the experiences of the communities. Discusses the new ecclesiological possibility that resulted in a Church which is born of the experience of grassroots communities. New ecclesial experience that aligns faith, social organization, study of the word of God and political participation. The article seeks to sew conciliar elements and the experiences of the meetings of bishops in the conferences of the Latin American Episcopate.

Keywords: Church, Community, Cebs, Popular.

"Igreja é povo que se organiza. Gente oprimida buscando a libertação."

O Concílio Vaticano II representou para a Igreja um momento de retomada de caminho. Não temos com certeza, uma visão unânime do concílio, pois "alguns acham que o Concílio Vaticano II foi um acontecimento acidental e pouco feliz: não Ihe reconhecem nenhum efeito positivo e atribuem-Ihe muitos efeitos negativos". ${ }^{2}$

\footnotetext{
1 Doutorado em Ciências Humanas - História Social; membro do presbitério da Arquidiocese de Montes Claros; Professor titular da Universidade Estadual de Montes Claros; Coordenador do Programa de Doutorado em Ciências da Religião (PUC-SP/UNIMONTES).

${ }^{2}$ COMBLIN, José. Vaticano II: Ontem e Hoje. Vida Pastoral. p. 02.
} 
Diferente dos opositores Kloppenburg, Comblin e Beozzo juntam suas vozes para afirmar a positividade deste grande acontecimento da Igreja Universal. Da voz Profética de Comblin, temos o indicativo: "O Concílio Vaticano II foi o maior acontecimento do século para a Igreja Católica: tudo o que se fez na Igreja, pelo menos depois de 1968, recebeu o seu significado histórico no Vaticano II."3 Sem sombra de dúvidas, que a Igreja não mais seria a mesma. O Vaticano II trouxe toda uma atmosfera de renovação. O Concílio não representava uma reunião qualquer, mas um momento dos bispos do mundo inteiro se reunirem para discutir os grandes temas relevantes para a Igreja. Temas que serviriam para o momento histórico e para toda a trajetória que viria posteriormente seriam tratados naquele momento histórico em que a igreja preparava a grande reunião.

O Concílio Vaticano II tem um diferencial por não querer ser um concílio doutrinário. "O Concílio Vaticano II quis ser um concílio pastoral. João XXIII seu idealizador o pensou desde o início com uma finalidade Pastoral." $\mathrm{A}$ finalidade pastoral suaviza aquele grande momento eclesial, pois fugia ao rigorismo doutrinal que permanecia desde o Concílio de Trento. A pretensão pastoral alarga os horizontes e fronteiras do Concílio, pois o mesmo apresenta um novo olhar eclesial para os católicos de diversos lugares do planeta. O concílio não tinha a pretensão de ser um momento de afirmação de doutrinas. Uma nova postura mais generosa ia se firmando. Em mensagem à Humanidade no dia 20/10/62 lembrava João XXIII: "Procuraremos apresentar aos homens de nosso tempo, íntegra e pura, a verdade de Deus de tal maneira que eles a possam compreender e a ela espontaneamente assentir".

A atitude impositiva parecia dar lugar a uma postura dialogal. O Vaticano II evoca um novo tempo para a Igreja. Kloppenburg lembra que "sentir com a Igreja, no momento atual, significa sentir e sintonizar com o Vaticano II". 6 Sintonizar com o Concílio Vaticano II é colocar-se numa nova postura mais compatível com o mundo moderno. Se o passado fora marcado pelo espírito da imposição, o presente vislumbra uma perspectiva mais aberta para uma igreja de comunhão. Lembra Häring que uma das marcas do Concílio Vaticano II foi a ideia de colegialidade. O novo clima de participação sugeria que se deveria ouvir mais, dentro de uma

\footnotetext{
${ }^{3}$ Idem. p. 02

${ }^{4}$ KLOPPENBURG, B. Compêndio do Vaticano II. Constituições e Decretos e Declarações. p.08.

${ }^{5}$ Idem. p. 09.

${ }^{6}$ Idem. p.08.
} 
conjuntura onde "o tema da colegialidade era para mim muito importante, já no período Preparatório". 7

O ideal de tolerância que marca o concílio já podia ser encontrado na primeira sessão do mesmo quando João XXIII lembrava que "preferimos mais o remédio da misericórdia do que da severidade". ${ }^{8}$ A atitude de João XXIII é reafirmada por Paulo VI no discurso de abertura da segunda sessão no dia 29/09/1963, quando faz questão de reafirmar a finalidade pastoral do concílio lembrando que "a palavra deve ser geradora de vida e ação" ${ }^{9}$

Estava instaurada uma nova época, isto é, um novo tempo de abertura entendido por Beozzo "como uma dádiva e uma benção de Deus para a sua Igreja". ${ }^{10}$ Os debates que viriam a ser travados durante as sessões seguintes não ficariam ausente de tensões entre os grupos que davam direção para o concílio.

Häring, em seu texto "Minha participação no Concílio Vaticano II", lembra que o concílio não teria sido pensável sem a contribuição de inúmeros teólogos e cardeais de expressiva formação e abertura para as grandes questões emergentes na Igreja pré-conciliar. Lembra Häring que "sem o trabalho sacrificado e o sofrimento de inúmeros teólogos"11 o concílio não seria possível. Enumera John Henry Newman, Karl Rahner, Henri de Lubac, Yves Congar, E. Schillebeeckx, A. Bea, J. Ratzinger, M. D. Chenu, G. Philips ${ }^{12}$. Ficou como marca do concílio o espírito de colaboração entre Papa, bispos e teólogos.

O Concílio Vaticano II propunha de fato um "aggiornamento" da Igreja. É com certeza estes novos ares que possibilitariam o surgimento de uma igreja que tenha a rosto do povo nos diversos continentes. Monsenhor Guerry apresenta quatro condições para uma apresentação pastoral do Concílio. Em primeiro lugar que a doutrina seja revificada, isto é, entendiam naquele momento que o corpo doutrinário já não respondia os apelos da modernidade. Em segundo lugar que a doutrina seja apresentada de modo acessível, assimilável em linguagem clara e simples. Entendia Guerry que era "preciso exprimir a mensagem de Cristo através dos conceitos e

\footnotetext{
${ }^{7}$ HÄRING, Bernhard. Minha Participação no Concílio Vaticano II. REB, Vol. LV. p. 383

${ }^{7}$ KLOPPENBURG, B. Compêndio do Vaticano II. Constituições e Decretos e Declarações. p. 08

${ }^{8}$ Idem. p. 08

${ }^{9}$ BEOZZO, José Oscar. A Igreja Após o Vaticano II. p. 33.

${ }^{10}$ HÄRING, Bernhard. Minha Participação no Concílio Vaticano II. p. 380.

${ }^{12}$ Idem. p. 380
} 
linguagens dos diversos povos e adaptar o Evangelho na medida do possível à capacidade de todos e às exigências dos sábios". 13

A Constituição Pastoral "Gaudium et Spes" expressara o sentimento de uma Igreja que necessita compreender, escutar e falar ao mundo de hoje. É importante salientar que a ideia da "Gaudium et Spes" surge no final da I sessão em 1962 no discurso do cardeal Suenens no dia 04/12/1962. O primeiro esquema tinha como título "A presença da Igreja no mundo moderno". ${ }^{14}$ Este tema constituiu em um dos mais polêmicos. Como é sabido havia setores eclesiais que resistiam aos questionamentos colocados pela igreja naquele momento de mudança da história eclesiástica. A visão de uma igreja centrada na hierarquia predominou historicamente nos diversos setores da comunidade eclesial. A visão do leigo inculto sempre teve lugar nas discussões impedindo o entendimento de sua presença como sujeito atuante na vida da igreja. A elaboração do documento final da "Gaudium et Spes" levou pelo menos quatro anos desde a ideia em 1962 até sua votação e promulgação no dia 6 de dezembro de 1965. Lembra Paulo VI que "o encontro da Igreja com o mundo atual foi descrito em páginas admiráveis na última Constituição do Concílio. Toda pessoa inteligente, toda alma honrada deve conhecer essas páginas. Elas levam, sim, de novo a Igreja ao meio da vida contemporânea, mas não para dominar a sociedade, nem para dificultar o autônomo e honesto desenvolvimento de sua atividade, mas para iluminá-la, sustentá-la e consolá-la". ${ }^{15}$

O concílio tentou expressar na "Gaudium et Spes" a vontade de dialogar com todos os homens. Lembrar o documento conciliar que "o Vaticano II não mais hesita em dirigir a palavra somente aos filhos da Igreja e a todos os que invocam o nome de Cristo, mas a todos os homens". ${ }^{16} \mathrm{O}$ concílio refletia o clima de mudança que se colocava em andamento na sociedade. Havia uma percepção que o mundo não era mais o mesmo. Registra o concílio que "a inteligência humana dilata de certa maneira o seu domínio também sobre o tempo. Sobre o passado, pelo conhecimento histórico. Sobre o futuro, pela prospectiva e planificação. O progresso das ciências biológicas, psicológicos e sociais não só contribuem para que o homem

\footnotetext{
${ }^{12}$ KLOPPENBURG, B. Compêndio do Vaticano II. Constituições e Decretos e Declarações. p. 11.

14 "De Praesentia Ecclesiae in mundo hodierno" O primeiro esquema de 1962 foi modificado em Lovaina pelo cardeal Suenens que apresentou novo esquema em novembro 1963.

${ }^{15}$ KLOPPENBURG, B. Compêndio do Vaticano II. Constituições e Decretos e Declarações. p.142.

${ }^{16}$ G.S., n.․ 2 .
} 
se conheça melhor, mas fornece-Ihe também os meios de influenciar diretamente na vida da sociedade". ${ }^{17}$

A igreja tomava consciência que a história acelerava-se rapidamente. Reconhecia as dificuldades de seguir as demandas colocadas pela modernidade. Teria a Igreja dormido no tempo? Sua presença na clausura durante a idade média a fez perder a noção do progresso? A mentalidade centralizadora a fez perder de vista que a mesma era formada pelo povo de Deus?

A "Gaudium et Spes" sinaliza para a necessidade de repensar a sociedade que apontava para mudanças. Percebe a Constituição Pastoral em questão que "as instituições, as leis, os modos de pensar e agir legados pelos antepassados não parecem sempre bem adaptados ao estado atual das coisas". ${ }^{18}$ A consciência da mudança se colocava nos padres conciliares. Havia uma inquietude que pairava na sociedade e no interior da Igreja. As preocupações "ad intra" haviam obscurecido o horizonte eclesial. No momento histórico o Concílio Vaticano II não representava apenas uma vontade de reunir, mas de responder as mudanças que atingiam "amplamente as letras, as artes, a interpretação das ciências humanas e da história e as próprias leis civis, de tal modo que em conseqüência muitos se perturbem" ${ }^{19}$

A modernidade representava uma ameaça para a velha instituição que secularmente definia os destinos das artes, literatura, filosofia e da própria ciência. Ao fazer a experiência de perda, a igreja demonstra seu desconforto. Em nome dos valores cristãos desperta de sua sonolência e tenta erguer a voz em uma conjuntura conturbada. O espírito autoritário parece exaurir por alguns instantes. $\mathrm{O}$ ar de prepotência parece perder força para quem deseja ouvir. Ainda na "Gaudium et Spes" podemos encontrar a confirmação da brandura reinando sobre a tirania. $O$ documento conciliar indica que "o concílio tem a intenção antes de tudo de distinguir sob esta luz - luz nova - aqueles valores que hoje são de máxima estimação, relacionando-os à sua fonte divina" ${ }^{20}$

A abertura proposta pelo Vaticano II exprime um profundo espírito de tolerância. O Vaticano II teve a intenção de dialogar de forma positiva com o mundo emergente em questão. Lembra-nos Kloppenburg que "neste Vaticano II não temos

\footnotetext{
${ }^{17}$ G.S., n. $\stackrel{0}{ } 5$.

${ }^{18}$ G.S., n. 07 .

${ }^{19}$ G.S., n. 07 .

${ }^{20}$ G.S., n. 011.
} 
cânones ou a doutrina negativa ou o "quid sit de fide vitandum et damnandum", mas temos os capítulos ou a doutrina positiva ou o "quid sit de fide tenendum". ${ }^{21}$

O concílio faz o esforço para criar condições de diálogo com o mundo moderno. Por que dialogar com a modernidade? A modernidade "define-se através da razão cada vez mais liberada da religião e através do humanismo, e na ênfase atribuída à ciência e à política." $22 \mathrm{O}$ clima estalado começa a favorecer uma atitude política e religiosa que questionava o autoritarismo da religião. Ao perceber os ares da modernidade muitos procuraram satanizá-la como obra que viria destruir os valores eternos da fé cristã. Muitos cristãos "passaram a exaltar a tradição com os eternos valores do passado, entre os quais se destacam a obediência e submissão às autoridades constituídas, a ordem e a disciplina na organização social e eclesiástica". ${ }^{23}$

Na perspectiva de ZAJDSZNAJDER "o período moderno seria caracterizado pelo reconhecimento da importância decrescente ou nula do divino nos assuntos humanos; pela predominância da razão científica de natureza experimental, da indústria sobre a agricultura e da cidade sobre o campo; e pela afirmação de uma revolução política de natureza democrática." ${ }^{24}$ Entendemos que a atitude da igreja naquele momento histórico apresentava ambigüidade, pois, se de um lado parte dos fieis pediam abertura, do outro lado católicos tradicionalistas reivindicavam o fechamento. Matos recorda que "de um lado, estavam aqueles católicos que aceitam os avanços obtidos com a Revolução, sobretudo os ideais de liberdade e de democracia. Propõem uma modernização da igreja, a fim de coloca-la em sintonia com as aspirações da época." ${ }^{25} \mathrm{~A}$ atitude antagônica da igreja representava, por sua vez, desconfiança diante dos clamores de mudanças. Desconfiança de quem estava do lado de quem sempre mandou. Neste clima de tensão "outra força do catolicismo da época é formada por aqueles que militam a favor da restauração, ou seja, da conservação do modelo de cristandade, tipo medieval. Seus adeptos constituem a grande maioria na Igreja de então. Tomam posições intransigentes frente às novidades e declaram seu ódio à Revolução com sua bandeira de

\footnotetext{
${ }^{21}$ KLOPPENBURG, B. Compêndio do Vaticano II. Constituições e Decretos e Declarações. p.25.

22 ZAJDSZNAJDER, L. Ética Estratégia e Comunicação: na passagem da Modernidade à Pósmodernidade. p. 25.

${ }^{23}$ MATOS, H. Caminhando Pela História da Igreja. p. 13.

${ }^{24}$ ZAJDSZNAJDER, L. Ética, Estratégia e Comunicação: Na Passagem da Modernidade à PósModernidade. p.27

${ }^{25}$ MATOS, H. Caminhando Pela História da Igreja. p. 16.
} 
liberdade e igualdade para todos. A democracia não pode ser obra de Deus". ${ }^{26}$ Diante da necessidade de abertura Guerry enumera as duas últimas condições finais para a apresentação pastoral do concílio. O concílio se colocava em um momento forte de redefinição dos valores para o mundo emergente. A experiência brutal de um modelo político no leste europeu abria caminhos para a angústia que viria posteriormente ser tema de discussão no mundo da filosofia. Lev Chestov (18661938) e Nikolaev Berdjaev (1874-1948) inicia o grande sonho de discutir a tragédia humana. As experiências da $1^{\underline{a}}$ e $2^{\underline{a}}$ Guerra alimentavam ainda mais 0 questionamento que tomaria corpo posteriormente na França com o nome de existencialismo. ${ }^{27}$

As mudanças tornavam-se necessárias e o clima estava estalado. Pontua Barros que um modelo novo estava colocado, pois o Concílio Vaticano II colocava seus alicerces com duas questões básicas: o primado da palavra de Deus e com a renovação eclesiológica. ${ }^{28} \mathrm{Na}$ primeira questão o concílio coloca um quesito fundamental que é a necessidade do diálogo. O primado da palavra obscurece momentaneamente o primado da autoridade. No segundo aspecto indica o concílio para a distinção entre a "Igreja de Cristo" e Igreja Católica. Lembra a constituição Lumen Gentium que a "Igreja de Cristo", constituída e organizada neste mundo como uma sociedade, subsiste na Igreja Católica governada pelo sucessor de Pedro e pelos Bispos em comunhão com ele, embora fora de sua visível estrutura se encontre vários elementos de santificação e verdade". ${ }^{29}$

A Igreja de Cristo é a Igreja Católica, mas também não é a Igreja Católica. A controvérsia filosófica clássica colocada por Heráclito e Parmênides se coloca como necessidade para a elucidação do que se aponta neste momento singular da história da Igreja. Lembrando Boff, Barros retoma o conceito de "subsistit in" que quer dizer "concretiza-se". ${ }^{30}$

$\mathrm{Na}$ análise de Barros a Igreja Católica não foi capaz de dar conta das diferenças da existência de outros continentes. O episcopado reunido no concílio

\footnotetext{
${ }^{26}$ Idem. p. 17.

${ }^{27} \mathrm{O}$ existencialismo ou filosofia da existência é uma vasta corrente filosófica contemporânea que se afirma na Europa logo depois da Primeira Guerra Mundial. Este é um período considerado de crise.

C.F. REALE, G. ANTISERI, D. História da Filosofia. p. 593-625.

${ }^{28}$ BARROS, M. Por uma Igreja Conciliar e Pluralista. O Vaticano II, o Diálogo Inter-religioso e a vida consagrada. p. 95.

${ }^{29}$ Lumen Gentium, p.8.

${ }^{30}$ BOFF, Leonardo. Quién subvierte el concílio? Respuesta al cardinal Ratzinger a propósito de la Dominus Jesus. p. 37.
} 
não se deu conta de que havia um universo que se estendia em outros continentes. "O Concílio Vaticano II tratou da relação Igreja Católica com o mundo moderno ocidental, sem se dar conta das peculiaridades de outros continentes. Diferente da Europa no terceiro mundo, os anos 60 foram marcados por movimentos de libertação na África, tentativas revolucionárias e golpes militares em diversos países da América latina. O Concílio não falou diretamente a este mundo, quem fez isso foi a Teologia da libertação que procurou partir do mundo dos empobrecidos e colocou em prática o que João XXIII sonhava: uma Igreja serva e pobre". ${ }^{31}$

Freitas indica que o mais difícil no Vaticano foi exatamente "alcançar a difícil meta de articular os dois pólos, o da Grande Tradição e o do aggiornamento". ${ }^{32}$ Desta mesma perspectiva comunga Maccise quando traz à memória que "infelizmente, no período pós conciliar, o discurso teórico está sendo freqüentemente desmentido por uma práxis eclesial, caracterizada por um crescente centralismo, autoritarismo, dogmatismo e jurisdicismo, geradores de exclusão, ao estilo do modelo anterior de Igreja - sociedade perfeita". ${ }^{33}$

O concílio permitiu que a Igreja do rigor abrisse suas portas para a Festa. Com o Concílio Vaticano II a igreja quis se fazer verdadeiramente Povo de Deus. Nas palavras de João XXIII abria-se uma "flor de uma inesperada primavera". Lenz faz questão de registrar as transformações ocorridas. Entre várias sublinha o fato dos padres conciliares rejeitarem grande parte dos esquemas preparados anteriormente pela Cúria Romana. "O que se viu foram os 2.500 membros do Concílio tomarem a decisão corajosa de abandonar os 72 esquemas previamente elaborados pela Cúria Romana, em três anos de preparação e partir para a elaboração de textos novos, sobre os temas que eles discerniram como fundamentais, esquemas novos, reduzidos afinal a 16 textos oficiais". ${ }^{34}$

Uma grande confraternização universal acontecia na Europa abalada anteriormente por diversos acontecimentos tristes. Se a guerra fragmentava os seres humanos e semeava a violência o concílio trazia uma nova áurea de harmonia. O evento tornava-se uma grande festa. A festa vinha ornada com um espírito de pluralidade. "A abertura ao Espírito inspirou uma segunda atitude básica

\footnotetext{
${ }^{31}$ BARROS, M. Idem. p. 96

${ }^{32}$ FREITAS, M. C. O Vaticano II quarenta anos depois. p. 577.

${ }^{33}$ MACCISE, C. La Violencia en la Iglesia. Revista Testimonio. p. 03. Nota: Padre Camilo Maccise. Presidente da União Internacional de Superiores Religiosos. Superior Geral em Roma.

${ }^{34}$ LENS, Pe. Martinho. $\mathbf{O}$ que o Concílio Vaticano II tem a dizer hoje à vida religiosa? Desafios
} Sócio-Pastoriais. p.590. 
no trato das questões internas à Igreja: a atitude de escuta e de diálogo, como maneira mais evangélica de aproximar-se da verdade através da busca comum, na certeza de que o Espírito fala às diversas Igrejas e se manifesta através de cada participante. Diálogo com o mundo, mas também diálogo dentro da Igreja: entre o Papa e os demais membros do Concílio, entre os padres conciliares, entre bispos, teólogos e leigos". 35

Estava armada a grande tenda. No Vaticano II participaram observadores de 17 igrejas cristãs ${ }^{36}$ convidadas, outros credos e religiões puderam manifestar neste grande momento singular da história da Igreja. O que estava colocado provocava alegria em todos, "tem-se a nítida impressão de que a iniciativa do papa, vista com alto índice de aprovação pela opinião pública, católica ou não, foi recebida com perplexidade pelas autoridades máximas da Igreja." ${ }^{37}$

Toda esta fase preparatória do Concílio Vaticano II fora sem duvida o chão fecundo para balizar o alicerce profundo de uma Igreja que se entendesse como fundada no povo. Um sonho sempre acalentou o interior da igreja, ou seja, que de fato ela fosse o que os primeiros cristãos desejavam: Uma comunidade de Comunidades. Para que este sonho pudesse tomar forma na América Latina foi necessário buscar inspiração no Concílio Vaticano II que significou o momento inspirador para uma nova visão eclesiológica. Esta nova visão eclesiológica inspirada nas ideias conciliares juntam-se ao novo modo de fazer a experiência da Fé cristã. Uma canção entoada nos quatro cantos da Igreja do Brasil lembrará posteriormente este desejo ao fazer ressoar: "Novo jeito de sermos Igreja nós buscamos Senhor na tua mesa". Em Medellín os bispos já lembravam que "o apostolado dos leigos tem maior significado e maior densidade eclesial quando se apoiam no testemunho de equipes e comunidade de fé". ${ }^{38}$

Ao buscar um novo jeito de ser Igreja rompe-se o velho paradigma centralizador e vertical. Inspirando-nos nas palavras do Documento de Aparecida podemos dizer que a Igreja que nasce das Comunidades Eclesiais de Base tem um

\footnotetext{
${ }^{35}$ Idem. p.591.

${ }^{36}$ C.F. MARTINA GIACOMO. História da Igreja: De Lutero a nossos dias. p. 278. Tradução: Orlando Soares Moreira. Ed. Loyola: São Paulo, 1997, p.278. No Concílio Vaticano II "não se tratava, todavia, de tomar solenes posições negativas contra erros que se alastravam, mas de encontrar o modo melhor de expor a antiga doutrina nos novos tempos, de instaurar um diálogo com toda a humanidade. Não se deviam preparar condenações ou anátemas, estratégias de resistência e de contraposição à Sociedade Moderna, mas dar início a um diálogo com todos, próximos e distantes".

${ }^{37}$ MARTINA GIACOMO. História da Igreja: De Lutero a nossos dias. p. 279.

${ }^{38}$ Medellím. p.80
} 
novo odor do Espirito de Deus, pois só a proximidade nos faz amigos e nos permite apreciar profundamente os valores dos pobres de hoje. A opção pelos pobres deve conduzir-nos à amizade com os marginalizados da sociedade. Dia a dia os pobres se fazem sujeitos da evangelização e da promoção humana integral.

É importante pontuar que as Comunidades Eclesiais de Base surgem na década de 1960 como experiência de pequenos grupos que se reúnem para vivenciar a sua espiritualidade no interior da vida comunitária. Merece destaque que - Brasil pela sua vasta extensão territorial sempre sofreu com carência de vocações ordenadas. A ausência do elemento institucional, por sua vez não foi fator desanimador, ao contrário estimulou o engajamento de lideranças leigas comprometidas plantando a semente daquilo que viria chamar popularmente de Cebs. Lembra-nos o documento de Puebla que "além da família cristã, que é o primeiro centro de evangelização, o homem vive sua vocação fraterna, no seio da Igreja particular, em comunidades que tornam presente e operante o desígnio da salvação do Senhor, vivido na comunhão e na participação". ${ }^{39}$

O Brasil interiorano sempre esteve perto de Deus. Onde faltava uma Igreja de tijolo, ali estava uma Igreja povo de Deus. A presença forte das confrarias, dos oratórios, rezadores de terço, pastorinhas, foliões, bandeiras de diversos santos, cavalhadas, catopés, marujada, romarias e as mais diversas manifestações fizeram do território brasileiro um imenso campo de espiritualidade. O elemento institucional sempre fora um estranho nas festas populares católicas brasileiras. O povo sempre mostrou uma grande disposição para cultivar, propagar e defender a fé.

No nosso entendimento o Concílio Vaticano II foi a gota d'agua em um solo fecundo que clamava pela visibilidade da organização popular da Igreja latino americana. $O$ chão já estava pronto com a profunda religiosidade popular espalhada pelos quatro cantos do Brasil. As Comunidades Eclesiais de Base foram capaz de articular: Religiosidade popular, sabedoria bíblica, piedade popular, organização popular e consciência política. A combinação destes elementos suscitou na cabeça de muitos seguimentos da sociedade uma ideia de que as comunidades de base não passavam de uma célula revolucionária no interior do catolicismo brasileiro. Não entendiam que na verdade "a Igreja pouco a pouco foi desligando dos que detêm o poder econômico ou político, prescindindo de dependência e privilégio". ${ }^{40}$ Este

\footnotetext{
${ }^{39}$ Puebla 467.

${ }^{40}$ Puebla 471.
} 
espírito de maior engajamento fez surgir novos ministérios e uma nova mentalidade fundada na ideia de maior colaboração entre leigos e leigas, no interior da vida eclesial. A comunidade nascente é ainda um lugar privilegiado de inter-relação pessoal. Neste espaço a palavra toma lugar iluminando as vidas e as diversas situações da vida. Nas Cebs o compromisso com a família, trabalho, bairro e a comunidade local toma destaque. ${ }^{41}$ Em Puebla os bispos declaram sua opção clara e irrestrita ás comunidades de base nascentes nos diversos países da América Latina.

No que se refere à religiosidade popular assistimos na América latina um forte resgate de uma liturgia inculturada. Os elementos da cultura vieram para dentro da liturgia cotidiana. O simbólico se aproxima das pessoas. Os sinais comunicam a vida e o sofrimento do dia a dia. Em um continente onde as elites haviam satirizado as tradições camponesas, as Cebs trouxeram para dentro dos espaços institucionais enxada, foice e tambores. A introdução da nova simbologia parecia um descumprimento das normas litúrgicas oficiais e, portanto, uma ofensa à legítima liturgia cristã. Associado ao simbólico outro elemento importante é a centralidade da palavra de Deus. A Bíblia sai dos ambões de prata e ouro para vir para o chão da comunidade. Espalha pelo Brasil e América Latina um profundo sentimento de irmandade. As toalhas da latino américa vem forrar o chão do Brasil para receber a palavra de Deus. $O$ anel de tucum passa ser um símbolo dessa grande luta dos povos latino americanos por uma cultura de respeito e de paz. Em torno da palavra se formava uma nova consciência.

Se anteriormente o partido e o sindicado eram as únicas escolas de formação política, as Cebs se constituem como verdadeiras escolas de fé e vida. Em depoimento oral falava Dom Adriano Hipólito bispo de Nova Iguaçu na Baixada Fluminense que nas sessões de torturas os carrascos queriam saber quem era Dona Cebs e Dona Puebla. Evidenciava-se o perigo da leitura de uma literatura que tivesse o rosto latino-americano. Em torno da palavra de Deus a vida se tornava política e a política se tornava vida. Afinal a vida é um grande ato político e Jesus se fez um grande político quando enfrentou os poderes de sua época para defender os mais pobres e necessitados. O engajamento político das Cebs desperta em setores conservadores a impressão que as comunidades de base são ameaças aos poderes

\footnotetext{
${ }^{41}$ Puebla 477.
} 
estabelecidos. A voz do trabalhador rural, da mulher do campo, dos favelados, Sem terra, Negros, Indígenas e operários começam a ecoar. O repertório musical consistia em uma catequese oral que contrariava a velha catequese dos antigos manuais que exigia leitura e capacidade para interpretar textos teológicos de cunho dogmáticos. Os cantos dizem: "vou convidar meus irmãos trabalhados, operários, lavrados, biscateiros e outros mais. E vamos juntos celebrar a confiança de terra pão e paz...". Tal contexto evidenciava a necessidade de chamar o laicato para ocupar os lugares de onde foram escorraçados. Ao refletir sobre o lugar dos leigos o episcopado latino-americano lembrava que o laicato sofreu embates e conflitos por parte de grupos de repressão que foram responsáveis por sua dispersão nos diversos setores da sociedade. ${ }^{42}$

Uma Igreja viva nascia e se espalhava pela América Latina. $\mathrm{Na} \mathrm{V}$ Conferência Geral do Episcopado Latino-Americano e do Caribe uma evidência era visível: "na experiência eclesial de algumas Igrejas da América Latina e do Caribe, as Comunidades Eclesiais de Base têm sido escolas que têm ajudado a formar cristãos comprometidos com sua fé, discípulos e missionários do Senhor, como o testemunha a entrega generosa, até derramar o sangue, de muitos de seus membros". 43

Fazer a trajetória da Igreja que nasce do povo constitui um grande desafio e nos coloca diante de muitas interrogações. A fertilidade do tema desafia nosso imaginário. Os recortes podem ser os mais variados. Poderíamos ter partido neste texto de uma perspectiva que busca seus fundamentos nos textos bíblicos, ou quem sabe, na fecunda tradição da patrologia. Não fica distante também uma possibilidade de buscarmos elementos na profunda e profícua historia da Igreja. Aqui buscamos os elementos em um dos maiores eventos da Igreja nestes últimos séculos: O Concílio Vaticano II. Tentamos demonstrar que as raízes mais próximas da igreja que encontramos hoje se fundamentam nas experiências deste gigantesco Concílio.

Ainda hoje o Concílio é fonte de inspiração para a Igreja que queremos ser. Uma Comunidade de comunidades. Uma comunidade onde todos possam participar efetivamente dos destinos e da vida da comunidade. Entendemos que a resistência à igreja que nasce das comunidades será sempre um incomodo. A saudade de uma

\footnotetext{
${ }^{42}$ Puebla 621.

${ }^{43}$ Documento de Aparecida, ํㅡ 178
} 
instituição hierárquica de poder salta ainda aos olhos de muitos saudosistas que não conseguem vislumbrar uma igreja dissociada do poder estabelecido.

Parece incoerente, mas todos os documentos pós-conciliares, sobretudo as Conferencias latino americanas insistem em seu bojo na ideia que as comunidades é a possibilidade de sobrevivência da própria igreja no continente latino americano. Expressões como "Igreja popular", "comunidades de comunidade" e "comunidade eclesial de base" enchem documentos alimentando um sonho de uma igreja mais próxima da realidade da vivência espiritual e social do povo de Deus. Expressões que fomentam embates teológicos, ideológicos e filosóficos. Na verdade, uma pergunta continua sendo feita: que Igreja queremos? Pergunta difícil em um cenário com elementos conservadores que ainda entendem a experiência de fé enclausurada em paredes das grandes edificações dos santuários e catedrais. Por que tantos pronunciamentos e defesas de uma Igreja que não se consegue efetivar? Por que falamos em pastoral de quarteirão, conjunto e popular enquanto sonhamos com basílicas?

As Cebs continuam vivas, pois nasceram das experiências de lutas dos mais pobres da nossa sociedade. É igreja povo e que tem cara de povo. Canta em sua liturgia a vida sofrida de tantos que não tem voz e vez. É espaço iluminado como queria João XXIII ao pedir que a Igreja abrisse suas portas para que o mofo interno pudesse se dissipar. Se em um momento da história tivemos a notícia de que 0 verbo se fez carne, sonhamos com o grande dia do anuncio: a Igreja se fez povo.

\section{REFERÊNCIAS}

AZZI, Riolando. O Catolicismo popular no Brasil. Petrópolis: Vozes, 1978.

BARROS, Marcelo. Presbíteros de Hoje no Mundo de Amanha: Notas Sobre Identidade e espiritualidade dos Presbíteros. Revista Vida Pastoral, Jan/Fev, ano XLII, n'm 216, 2001.

BENEDETT, Luiz Roberto. Templo, Praça, Coração (articulação do campo religioso católico). 1988. Tese Doutorado, USP.

BENEDETTI, Luiz Roberto. Igreja, Difícil Busca de Identidade. Revista Vida Pastoral. Setembro/Outubro, N.112, ano XXIV, 1983.

BOFF, Leonardo. Igreja Carisma e Poder. 3edição, Ed. Vozes, Petrópolis, 1982. 
BOFF, Leonardo. Saber Cuidar. Petrópolis. Vozes, 1999.

BRUNEAU, Thomas. Catolicismo brasileiro em época de Transição. São Paulo: Loyola, 1974.

COMBLIN, J. Os Interrogantes da Vida Religiosa no Século XXI. Revista Convergência. CRB. Março. Rio de Janeiro. 2004.

GALEANO, Eduardo. As veias abertas da América Latina. Trad. Galeno de Freitas. Rio de Janeiro: Paz e Terra, 1989.

HOORNAERT, Eduardo (org). Das reduções latino-americanas as lutas indígenas atuais. IX Simpósio latino-americano da CEHILA. São Paulo: Paulinas, 1982.

LE GOFF, Jacques. Historia e memória. Trad. Bernardo Leitão. Campinas, SP: Unicamp, 1996.

LIBÂNIO, João Batista. A Volta à Grande Disciplina. São Paulo: Loyola, 1983.

MUÑOZ, Ronaldo. Nova consciência da igreja na América Latina. Trad. Jorge Soares. Petrópolis: Vozes, 1979.

OLIVEIRA, Pedro Ribeiro de. Religião e Dominação de Classe. Petrópolis: Vozes, 1985.

RIBEIRO, Helcion. Religiosidade popular na teologia latino-americana. Edições Paulinas, s.d.

ROLIM, Francisco Cartaxo. Religião e classes populares. Petrópolis: Vozes, 1980.

STEIL, Carlos Alberto. O Sertão das Romarias: Um Estudo Antropológico Sobre o Santuário de Bom Jesus da Lapa- Bahia. Ed Vozes, Petrópolis, 1996.

TORRES, João Camilo de Oliveira. História das idéias religiosas no Brasil. São Paulo: Gryalbo, 1968.

VV.AA. Historia da igreja no Brasil. Tomo II/2 (Segunda época - século XIX), ed. Paulinas/Vozes/ CECHILA, 1992.

VV.AA. Historia da igreja no Brasil: ensaio de interpretação a partir do povo (primeira época). Ed. Vozes/Paulinas/CEHILA, 1992. 